\title{
INCREASE THE ABSORPTION PLASM AND THE FLOW OF LIGHT ENERGY IN ULTRA-THIN FILMS GAAS SOLAR NANO-STRUCTURED METAL
}

\author{
E. Amidi
}

Master of Atomic and Molecular Physics, Islamic Azad University, Mahanadi

Published online: 15 May 2016

\begin{abstract}
The silicon thin film solar cells in the visible region, The low absorption which reduces its efficiency. The use of metallic nanostructures help, to increase light absorption and reduce the size of the entire structure will be. The process of light absorption in solar cells is one of the factors in improving the performance of solar cells. Silicon thin film solar cells, in the visible region, the absorption is low. Using arrays of metallic nanostructures, Semiconductors such as silicon or germanium on, Radiation absorption, a significant amount used in the top layer. Metal nanostructures for their ability to excite PLASMONS, (Collective oscillations of free electrons) are being considered. PLASMONS, surface electromagnetic waves, They are strictly limited to the field level, And that's why the border field strength is high, As a result, the surface PLASMON excitation, Square in the vicinity of heavily reinforced silicon and thus the absorption of light, The silicon layer is increased significantly.
\end{abstract}

Keyword: Plasmon light energy; NANO-structured metal.

Author Correspondence, e-mail: authorC@gmail.com

doi: http://dx.doi.org/10.4314/jfas.v8i3s.171

\section{INTRODUCTION}

The flow of light energy, And ultra-thin films for solar cells, GA gallium arsenic-coated metal nanoparticles To show to help increase the absorption of metal nanoparticles, GA As solar cells, thin light, (IE, the absorption> intentionally designed with a thick layer absorbent), P- 
type emitter with a thickness of 50nm, On top of a thick n-type base 150nm, Metal-organic chemical vapor deposition grew up with. Density of metal nanoparticles directly, Aperture layer $0.8 \mathrm{Ga} 0.2 \mathrm{As}$, gallium arsenic cells within the pores of alumina, Alumina membrane coating emitted by thermal evaporation Light-thin solar cell structure of gallium arsenic, From the top to the bottom cells made of layers of contact P-type GA As with a thickness of 300nm (concentrated liquid $\mathrm{Zn}$,), Selected with chemical acid to remove metal contacts, Aperture layer, p-type GA As emitter layer with a thickness of 50nm, Gallium arsenic n-type layer with a thickness of $150 \mathrm{~nm}(\mathrm{Si}, 2 * 1017 \mathrm{~cm}-3)$, The rear surface of the n-type layer with a thickness environmental 500nm, Gallium arsenic n-type buffer layer grown to a thickness of 1um, And n-type GA As substrate between the Ag particle diameter nm 50-150, And range between 100-300nm, The shape of the particles to form a vertical circular cylinder. Ag nanoparticles completely within each cell sample size, Because of the same aperture size and spacing, the uniform alumina membrane coating, that's why the aperture diameter during the preparation, the membrane is carefully controlled. Height with thick metal nanoparticles deposited in the process, Thermal evaporation easily controlled. Figure 1 and Figure Scanning electron, Cover Ag nanoparticles with a diameter of $60 \mathrm{~nm}, 10 \mathrm{~nm}$ to $75 \mathrm{~nm}$ with the height range, Solar cells, and gallium arsenic shows.

Spectral response measurements, Solar cells, gallium arsenic "optical thin" made, No metal nanoparticles of silver and aluminum, to determine the effect of metal nanoparticles used.

\section{MODELING}

To understand the full role of NANO solar cells gallium arsenic, A simple model light absorption increases, In converting light energy into electrical layers, On top of metal nanoparticles and is created as follows. For convenience, we have only light energy conversion layer, the electrical outlet Al GA As layers is considered negligence. (Note that the refractive indexes $\mathrm{Al}$ GA As are the same gallium and arsenic). For light radiation absorption in the layer thickness $\mathrm{L}$ is as follows:

(Equation . 1)

$$
A_{0}(\lambda)=1-\exp (-\alpha(\lambda) L)
$$

Wavelength in a vacuum. That, $\alpha$ constant absorption of arsenic and gallium been shown $\lambda$ Angular distribution of emitted light intensity, Packed with sub-wavelength size particles such as KVASYSTATY: 


$$
I_{s c o} \propto\left(1+\cos ^{2} \theta\right) I_{0}
$$

(Equation 2)

$\theta$ angle is measured from the front of propagation paths. Published for light absorption is as follows:

(Equation 3)

$$
A_{\theta}(\lambda)=\int_{0}^{\pi / 2} \frac{1+\cos ^{2} \theta}{\int_{1}^{2}\left(1+\cos ^{2} \theta\right) d \theta}\left\{1-\exp \left(-\alpha(\lambda) \frac{L}{\cos \theta}\right)\right\} d \theta^{.}
$$

Despite the fact that the optical path in the layer of gallium arsenic, From L to LICOS $\theta$ increases. Total absorption layer gallium arsenic Ross and surface coating nanoparticles with $\xi$ as follows:

$$
A_{\text {tot }}(\lambda)=\xi Q_{\text {ext }}(\lambda) \eta_{\text {rad }}(\lambda) A_{\theta}(\lambda)+\left(1-\xi Q_{e x t}(\lambda)\right)(1-R(\lambda)) \Lambda_{0}(\lambda)
$$

(Equation 4)

QEXT and $\eta$ rad reduce the operating efficiency of the light, And exposure to nanoparticles as defined in reference 6 and 2. $\xi 0.4$ and 0.3 for $60 \mathrm{~nm}$ and $150 \mathrm{~nm}$ diameter of the order was, As of electronic microscope images is determined. Values for QEXT and rad with bipolar elliptical particles, Metal and at least equal to the incident light axis responsive, The height of the attack KVASYSTAYK experimental nanoparticles, Using effective medium approximation, Complex dielectric function of the media were calculated. Especially for nanoparticles Al, QEXT and $\eta \mathrm{rad}$ for concentration, Al-Al2O3 core-shell particle density oval with, Al2O3 shell thickness of $4 \mathrm{~nm}$ in accordance with, Al particles in the atmosphere, surface oxidation were calculated. Reflectivity $\mathrm{R}$ in connection with gallium arsenic, Also was regarded as solar cells, GA As, There is no anti-reflective coating or surface structure. Assuming normal radiation of light within the layers of GA As, Based on independent reflectivity wavelength is:

$$
R(\lambda)=\frac{1,(\lambda)}{l_{11}(\lambda)}=\frac{N_{2}(\lambda)-N_{1}(\lambda)}{N_{2}(\lambda)+N_{1}(\lambda) \mid}
$$

The $\mathrm{N}$ complex refractive index of air is gallium or arsenic. 


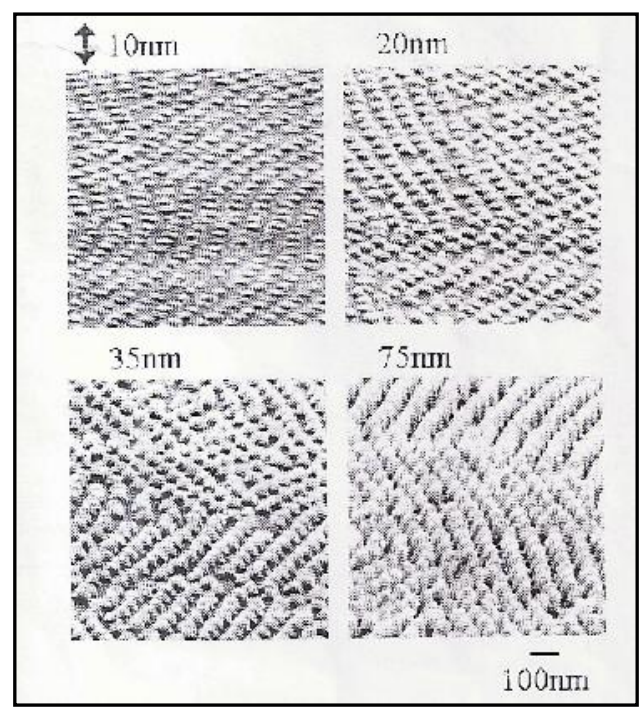

Fig.1. Check Scanning Electron Microscopy (SEM) of, Array Ag nanoparticles with a diameter of $60 \mathrm{~nm}$, Lees height range of 10 to $75 \mathrm{~nm}$, GA As solar cell on a 75-degree angle

Based on these assessments, Improvements in the flow of pure light energy, not only for the wavelength range above, but also major efficiency achieved for optimal conditions. However, we only minor progress, In the course of luminous energy, and efficiency due to thick absorbent substrate, Gallium arsenic in the presence of cellular structures ever have seen. Structures such as a refractive index greater wavelength, layer and low index material, Underlay and led to the confrontation, light rise higher and usually during the production.

\section{Ultra-slim metallic NANO-structured solar cells, gallium arsenide plate with steel rear}

\section{structure of experimental work}

Wave solar cell structure such as GA As with a layer of metal GHQB ,in summary, Figure 3 shown on the left, the link-layer back sheet and transfer the acid to be selected, Home-grown GA As material was provided. As well as cells with thick GA As layer $3 \mu \mathrm{m}$, that imitates the absorbent material has been corrected As well as the reference to the right of Figure 3 is shown. Pictures locations, or topology represents a cross-cell communication, Gallium arsenic - Silver roughness based on the size of the wave, The range is $20 \mathrm{~nm}$, So we connect the incident light into polarized modes, Or surface PLASMON waveguide modes that photonics has published numerous angles, We expect to increase absorption. 


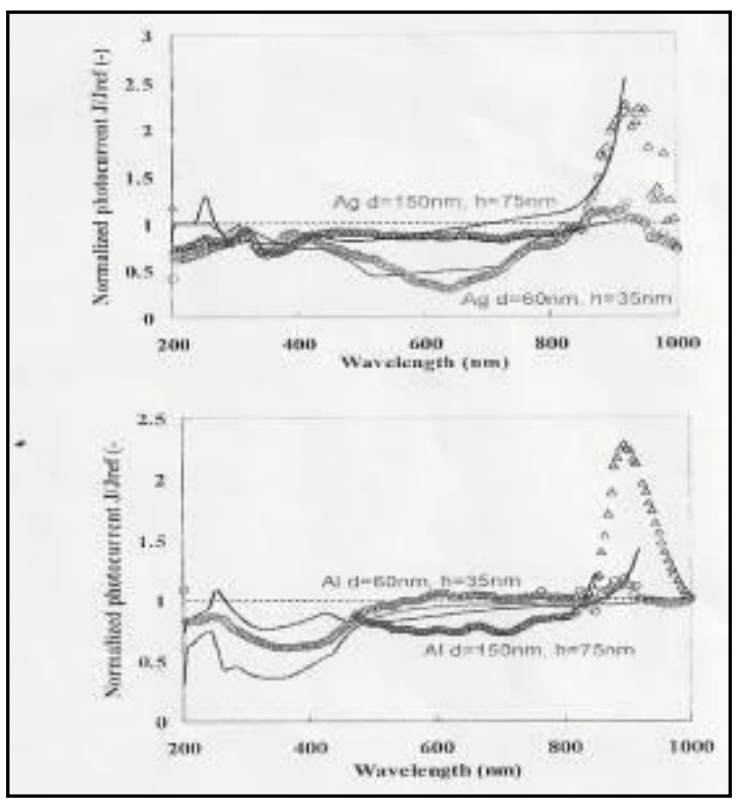

Fig.2. Optical flow normal range for solar cells, GAAs nanoparticles (a) Ag and (b) Al .JZI curves normalized optical model, Plotted is calculated

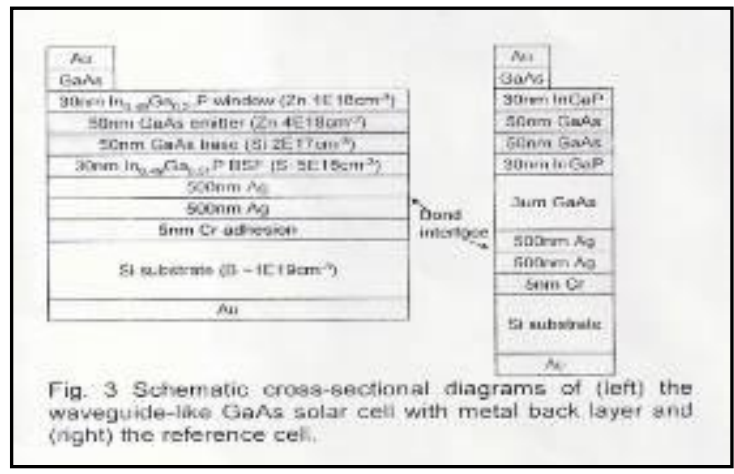

Fig.3. Cross section sketch of the graph (left), solar cell wavelengths, such as GAAs, with metal rear layer $(\mathrm{R})$ cell source

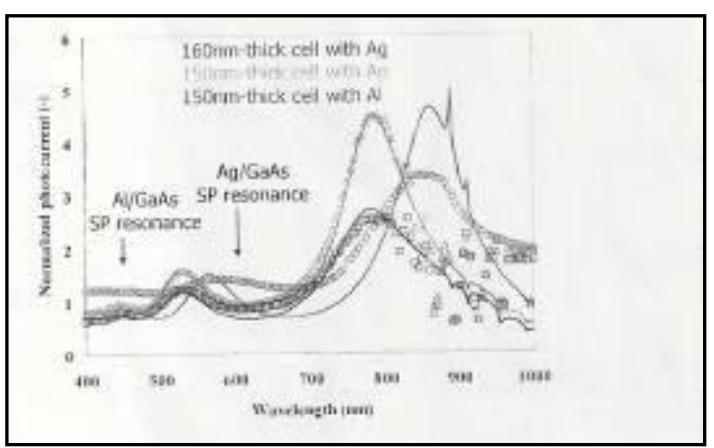

Fig.4. Light I-V curves for conventional solar cells, Wavelengths such as GaAs cells with Ag rear structure, GAAs source of the solar spectrum AM1.5G 1-sun 


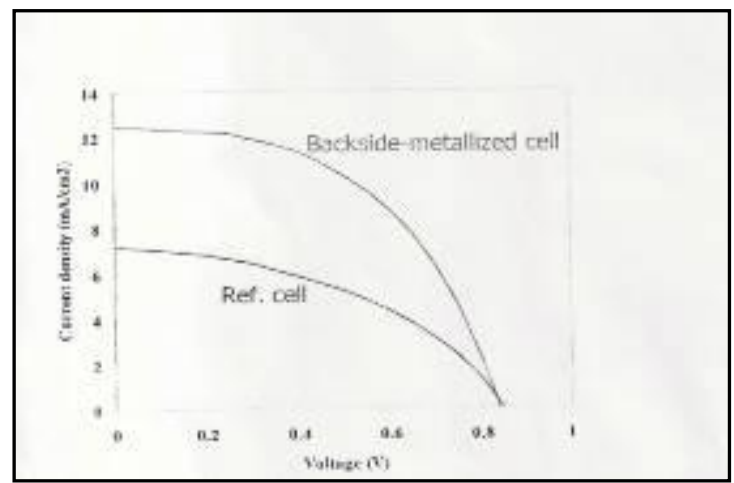

Fig.5. During normal light wavelength spectrum solar cell, Such as GAAs cells with light streaming source. (Points) JZI normal, Solar cells such as GAAs for wavelengths in accordance with the work, FABRY -Perot resonance in GAAs thin layer at the back and vector layers, MAZI KX wave communication metal / GAAs calculated and plotted (lines)

\section{RESULTS AND DISCUSSION}

Figure 4 shows a typical light curves I-V, for cells such as GAAs wavelength with, Ag rear structure and source of cells, GAAs, Shows the solar spectrum. Short-circuit current considerably for the cells, Ag structure is larger. Figure 5 (the triangle) of the normal range, Wavelength dividing cells such as by, Shows the flow of light energy source of cells This light $\mathrm{I}-\mathrm{V}$ and the results show that the spectral response, Metal back GAAs cell is a general increase, The wavelengths of light energy for all offers. 600nm and 900nm normal NVRRVANGY in Figure 5 shows two peaks. To communicate the release of GAAs / Ag, Surface PLASMON resonance as seen in Figure 5, was found in 600nm. A possible reason for the resonance peak 600nm, Surface PLASMON in GAAs / Ag was, leading to increased uptake by dropping PLASMON of incident light into surface PLASMONS is expanded.

However, the increase calculated optical multilayer, FABRY-Perot represent the effect of absorption in thin layers and active GA As, The rear surface is reflected in Figure 5 (lines) are shown, A peak for the normalized absorbance, Was found at about $600 \mathrm{~nm}$ and amplitude ratio, Two peaks correspond with the calculation result. Also, the two couriers were found to change, FABRY -Perot calculation results as the cell thickness varies. In addition, peaks at the same wavelength, Hind Al cell with a layer despite the differences, the relationship between the surface PLASMON resonance wavelength, GA As / Ag and GA As / Al was found. For these reasons, increase the flow of light energy, Wavelength observed for cells 
such as GA As, With the help of metal behind the messenger, 600nm and $900 \mathrm{~nm}$ are specified in, FABRY -Perot resonance bind No PVLARYTVN proliferation of surface PLASMONS at the interface of GA As / metal.

\section{REFERENCES}

[1] C.R. Mayer, E. Dumus, F. Secheresse, Chem. Commun. (2005) 345.

[2] J. Zeng, J. Huang, W. Lu, X. Wang, B. Wang, S. Zang, J. Hou, Adv. Mater. 19 (2007) 2172.

[3] C. Lu, J. Gao, Y. Fu, Y. Du, Y. Shi, Z. Su, Adv. Funct. Mater. 18 (2008) 1.

[4] G.D. Scholes, Adv. Funct. Mater. 18 (2008) 1157.

[5] B. Leger, A. Denicourt-Nowicki, A. Roucoux, H. Olivier-Bourbigou, Adv. Synth. Catal. 350 (2008) 153.

[6] J.K. Lim, S.W. Joo, Surf. Interf. Anal. 39 (2007) 684.

[7] Z. Cao, H. Fu, L. Kang, L. Huang, T. Zhai, Y. Ma, J. Yao, J. Mater. Chem. 18 (2008) 2673.

[8] L.M. Liz-Marzan, P. Mulvaney, New J. Chem. (1998) 1285.

[9] S. Nath, S.K. Ghosh, S. Praharaj, S. Panigrahi, S. Basu, T. Pal, New J. Chem. 29 (2005) 1527.

[10] L.F. Hakim, D.M. King, Y.Zhou, C.J. Gump, S.M. George, A.W. Weimer, Adv. Funct. Mater. 00 (2007) 1.

[11] D.-W. Kim, J.-M. Lee, J.-J. Lee, P.-Y. Kang, Y.C. Kim Seong-Geun Oh, Surf. Coat. Technol. 201 (18) (2007) 7663.

[12] B. He, J.J. Tan, K.Y. Liew, H. Liu, J. Mol. Catal. A: Chem. 221 (2004) 121.

[13] A.K. Singh, V.S. Raykar, Colloid Polym. Sci. 286 (2008) 1667.

[14] A.M. Junior, H.P.M. Oliveira, M.H. Gehlen, Photochem. Photobiol. Sci. 2 (2003) 921.

[15] C.P. León, Vibrational Spectroscopy of Photosensitizer Dyes for Organic Solar Cells, Cuvillier Verlag, 2005, pp. 55-56.

[16] T. Kondo, S.M. Lee, M. Malicki, B. Domercq, S.R. Marder, B. Kippelen, Adv. Funct. Mater. 18 (2008) 1112.

[17] I. Pastoriza-Santos, C. Serra-Rodriguez, L. Liz-Marzan, J. Colloid Interf. Sci. 221 (2000) 236.

[18] M. Muniz-Miranda, G. Sbrana, J. Mol. Struct. 565 (2001) 159.

[19] S. Zhao, K. Zhang, J. An, Y. Sun, C. Sun, Mater. Lett. 60 (2006) 1215.

[20] C. Du, B. Xu, Y. Li, C. Wang, S. Wang, Z. Shi, H. Fang, S. Xiao, D. Zhu, New J. Chem. 25 (2001) 1191.

[21] J. Gingras, H. Jean-Philippe Dery, E. Yockell-Lelievre, A.M. Borra, Ritcey, Colloid Surf. Physicochem. Eng. Aspects 279 (2006) 79.

[22] D. Radziuk, A. Skirtach, G. Sukhorukov, D. Shchukin, H. Mohwald, Macromol. Rapid Commun. 28 (2007) 848.

[23] M. Puchalski, P. Dąbrowski, W. Olejniczak, P. Krukowski, P. Kowalczyk, P. Polański, Mater. Sci. Poland 25 (2) (2007) 473.

[24] D.D. Evanoff Jr., G. Chumanov, Chemphyschem 6 (2005) 1221.

[25] H. Chang, C. Jwo, C. Lo, T. Tsung, M. Kao, H. lin, Rev. Adv. Mater. Sci. 10 (2006) 128. 
How to cite this article:

Amidi E. Increase the absorption plasm and the flow of light energy in ultra-thin films gaas solar nano-structured metal. J. Fundam. Appl. Sci., 2016, 8(3S), 129-136. 